\title{
Splanchnic and Peripheral Glucose and
}

\section{Amino Acid Metabolism in Diabetes Mellitus}

\author{
John Wahren, Phimip Felig, Erol Cerasi, and Rolf Luft \\ From the Department of Clinical Physiology, the Seraphimer Hospital, 11283 \\ Stockholm, the Department of Internal Medicine, Yale University School of \\ Medicine, New Haven, Connecticut 06510, and the Department of Endocrinology \\ and Metabolism, the Karolinska Hospital, 10401 Stockholm 60, Sweden
}

\begin{abstract}
A в S T R A C T Splanchnic and leg exchange of glucose, lactate, pyruvate, and individual plasma amino acids was studied in diabetics $24 \mathrm{hr}$ after withdrawal of insulin and in healthy controls. Measurements were made in the basal postabsorptive state and during the administration of glucose at a rate of $2 \mathrm{mg} / \mathrm{kg}$ per min for $45 \mathrm{~min}$.
\end{abstract}

In the basal state, net splanchnic glucose production did not differ significantly between diabetics and controls. However, splanchnic uptake of alanine and other glycogenic amino acids was $1 \frac{1}{2}-2$ times greater in the diabetics, while lactate and pyruvate uptake was increased by $65-115 \%$. Splanchnic uptake of these glucose precursors could account for $32 \%$ of hepatic glucose output in the diabetics, as compared to $20 \%$ in the controls. This increase in precursor uptake was a consequence of a two- to threefold increment in fractional extraction of these substrates inasmuch as arterial levels of alanine, glycine, and threonine were reduced in the diabetics, while the levels of the remaining substrates were similar in the two groups. Peripheral output of alanine and other glycogenic amino acids as reflected in arterio-femoral venous differences was similar in both groups. An elevation in arterial valine, leucine, and isoleucine was observed in the diabetics, but could not be accounted for on the basis of altera-

A preliminary report on some of the results was presented at the International Symposium Commemorating the 50th Anniversary of Insulin, Jerusalem, Israel, 25 October 1971 (1).

Dr. Felig is a Teaching and Research Scholar of the American College of Physicians.

Address reprint requests to Dr. Philip Felig, Department of Internal Medicine, Yale University School of Medicine, New Haven, Conn.

Received for publication 28 December 1971 and in revised form 7 February 1972. tions in splanchnic or peripheral exchange of these amino acids.

Administration of glucose ( $2 \mathrm{mg} / \mathrm{kg}$ per $\mathrm{min}$ ) for $45 \mathrm{~min}$ resulted in an $80 \%$ reduction in splanchnic glucose output in controls, but failed to inhibit hepatic glucose release in the diabetics despite a twofold greater increment in arterial glucose levels. In both groups no consistent changes in arterial glucagon were observed during the infusion.

It is concluded that in nonketotic diabetics $(a)$ total splanchnic output of glucose is comparable to controls, but the relative contribution of gluconeogenesis may be increased by more than $50 \%$; $(b)$ accelerated splanchnic uptake of glucose precursors is a consequence of increased hepatic extraction of available substrates rather than a result of augmented substrate supply; and (c) the failure of glucose infusion to inhibit hepatic glucose output suggests that the exquisite sensitivity of the liver to the infusion of glucose in normal man is a consequence of glucose-induced insulin secretion.

\section{INTRODUCTION}

The contribution of altered hepatic glucose balance to the metabolic defect in diabetes mellitus has long been the subject of inquiry and debate. Numerous investigations employing the hepatic venous catheter technique $(2,3)$, or isotope dilution methods $(4-6)$, have provided data on the net rate of hepatic glucose release and on systemic glucose turnover in diabetic patients. Little is known, however, about the effect of diabetes on the hepatic uptake and peripheral release of glucose precursors. Specifically, the question of whether an augmentation in substrate availability or alterations in 
TABLE I

Clinical Data for Diabetic Subjects

\begin{tabular}{lccccccc}
\hline Subject & Age & Height & Weight & $\begin{array}{c}\text { History of } \\
\text { diabetes }\end{array}$ & $\begin{array}{c}\text { Duration of } \\
\text { insulin } \\
\text { therapy }\end{array}$ & $\begin{array}{c}\text { Dose of } \\
\text { lente } \\
\text { insulin* }\end{array}$ & $\begin{array}{c}\text { Arterial } \\
\text { blood } \\
\text { glucose }\end{array}$ \\
\hline & $y r$ & $c m$ & $k g$ & $y r$ & $y r$ & $I U$ & $m g / 100 m l$ \\
C. C. & 26 & 166 & 55 & 12 & 12 & $20+8$ & 302 \\
L. K. & 48 & 174 & 68 & 2 & 1 & 32 & 308 \\
H. L. & 19 & 184 & 70 & 4 & 4 & $32+28$ & 267 \\
K. W. & 26 & 179 & 72 & 3 & 3 & $16+12$ & 170 \\
T. J. & 24 & 173 & 60 & 15 & 15 & $32+12$ & 264 \\
G. W. & 28 & 181 & 67 & $9 \frac{1}{2}$ & $9 \frac{1}{2}$ & $56 \ddagger$ & 193 \\
L. B. & 28 & 178 & 55 & 9 & 9 & 40 & 228 \\
\hline
\end{tabular}

* Where two numbers are given they represent morning and evening doses of insulin, respectively. $\ddagger$ Includes $20 \mathrm{IU}$ protamine zinc insulin, all other patients received only lente insulin.

intrahepatic processes are responsible for accelerated gluconeogenesis in diabetes has not been resolved. The answer to this question is not only of importance to our understanding of diabetes, but is of direct relevance to elucidating the mechanism by which insulin regulates gluconeogenesis (7). Furthermore, identification of the quantitative relationships between hepatic glucose output and the uptake of precursor substrates provides information not available from previous catheter or isotope studies on the relative contributions of gluconeogenesis and glycogenolysis to total splanchnic glucose production in diabetes.

The present study was consequently undertaken to examine in man the supply and uptake of gluconeogenic precursors in diabetes. Splanchnic and peripheral exchange of glucose, amino acids, lactate, and pyruvate was examined in insulin-dependent diabetic patients and in normal controls. In addition, the role of endogenous insulin secretion in the exquisite sensitivity of hepatic glucose production to small changes in blood glucose concentration first shown by Madison, Combes, Adams, and Strickland in dogs with portacaval shunts (8), and more recently demonstrated in normal human subjects (7), has been further substantiated by evaluating the effect of a similar glucose infusion $(2 \mathrm{mg} /$ $\mathrm{kg}$ per min) on splanchnic glucose balance in insulindependent diabetics.

\section{METHODS}

Subjects and procedures. Seven male, nonobese patients with insulin-dependent diabetes mellitus of several years duration were studied. Clinical data are given in Table I. The patients were in good nutritional balance and ingested a weight-maintaining diet consisting of approximately $40 \%$ carbohydrate and $25-35 \%$ each of protein and fat. All were followed at regular intervals of 2-3 months in the outpatient department. No patient had had periods of weight loss or episodes of hypoglycemia during the 1-2 yr before study. There was no history or evidence of liver disease and none were alcoholics. None of the patients had symptoms or signs of peripheral vascular disease. At the time of the study all of the subjects were actively employed. The nature, purpose, and possible risks involved in the catheterization procedure were carefully explained to the patients before obtaining their voluntary consent to participate.

The studies were performed in the morning after an overnight fast $(12-14 \mathrm{hr}$ ). Insulin was withheld for $24 \mathrm{hr}$ before the study. (The morning dose of insulin was not given on the day of the study, while those patients receiving two daily doses [Table I] were not given their evening dose on the preceding day.) Teflon catheters were inserted precutaneously into a brachial artery, a femoral vein, and an antecubital vein. A Goodale-Lubin catheter (No. 7 or 8 ) was then inserted into an exposed antecubital vein and advanced under fluoroscopic control to a right-sided hepatic vein. The tip of the catheter was placed $3-4 \mathrm{~cm}$ from the wedge position and its location was checked repeatedly by fluoroscopy during the study. Patency of the catheters was maintained throughout the study by flushing with saline intermittently. Heparin was not employed during the study.

After the catheters were in place, simultaneous arterial, hepatic venous, and femoral venous blood samples were drawn repeatedly for chemical analyses and for hepatic blood flow determination during a 30-45 min control period. Glucose was then infused intravenously at a rate of $2 \mathrm{mg} / \mathrm{kg}$ per min for $45 \mathrm{~min}$ during which time additional blood samples were obtained at 5- to 10-min intervals. One of the diabetic subjects was studied in the basal state only.

The control group consisted of 24 healthy, nonobese, adult male volunteers, 21-52 yr of age. All but one of these subjects have been described in detail in previous reports from our laboratories $(7,9,10)$. Seven of these subjects (including the one individual not described previously) were studied in the basal state and during the course of the $45 \mathrm{~min}$ glucose infusion (7). For the remaining subjects observations were made in the basal state only.

Analyses. The methods employed for the determination of hepatic blood flow and for measurement of blood glucose, lactate, pyruvate, and oxygen, individual acidic and neutral plasma amino acids, and plasma insulin have been described previously $(7,9,10)$. Glucagon was measured in plasma by radioimmunoassay (11) using an antibody kindly supplied by Dr. Roger Unger (lot $30 \mathrm{~K}$ ). Arterial blood $\mathrm{pH}$ and $\mathrm{P}_{\mathrm{CO}_{2}}$ were determined with a BMS-3 electrode system (Radiometer Co., Copenhagen, Denmark). 
TABLE II

Arterial Concentration, Arterial-Femoral Venous Differences $(A-F V)$, Arterial-Hepatic Venous Differences $(A-H V)$, and Splanchnic Exchange of Glucose, Lactate, Pyruvate, and Oxygen in Diabetic $(n=7)$ and Control Subjects $(n=24)^{*}$

\begin{tabular}{|c|c|c|c|c|c|}
\hline & & $\begin{array}{c}\text { Arterial } \\
\text { concentration }\end{array}$ & $A-F V$ & $A-H V$ & $\begin{array}{l}\text { Splanchnic } \\
\text { exchanget }\end{array}$ \\
\hline & & mmoles/liter & mmoles/liter & mmoles/liter & mmoles/min \\
\hline Glucose & $\begin{array}{l}\text { Diabetics } \\
\text { Controls }\end{array}$ & $\begin{aligned} 13.85 & \pm 0.64 \S \\
4.08 & \pm 0.06\end{aligned}$ & $\begin{array}{l}0.15 \pm 0.07 \\
0.19 \pm 0.02\end{array}$ & $\begin{array}{l}-0.78 \pm 0.07 \\
-0.80 \pm 0.08\end{array}$ & $\begin{array}{l}-1.07 \pm 0.08 \\
-0.95 \pm 0.11\end{array}$ \\
\hline Lactate & $\begin{array}{l}\text { Diabetics } \\
\text { Controls }\end{array}$ & $\begin{array}{l}0.66 \pm 0.03 \\
0.70 \pm 0.03\end{array}$ & $\begin{array}{l}-0.20 \pm 0.02 \\
-0.14 \pm 0.03\end{array}$ & $\begin{array}{l}0.28 \pm 0.02 \| \\
0.21 \pm 0.02\end{array}$ & $\begin{array}{l}0.41 \pm 0.04 \pi \\
0.25 \pm 0.04\end{array}$ \\
\hline Pyruvate & $\begin{array}{l}\text { Diabetics } \\
\text { Controls }\end{array}$ & $\begin{array}{l}0.073 \pm 0.003 \\
0.069 \pm 0.002\end{array}$ & $\begin{array}{l}-0.008 \pm 0.003 \\
-0.002 \pm 0.002\end{array}$ & $\begin{array}{l}0.025 \pm 0.003 \| \\
0.014 \pm 0.004\end{array}$ & $\begin{array}{l}0.037 \pm 0.004 \S \\
0.017 \pm 0.003\end{array}$ \\
\hline Oxygen & $\begin{array}{l}\text { Diabetics } \\
\text { Controls }\end{array}$ & $\begin{array}{l}8.28 \pm 0.16 \\
7.99 \pm 0.09\end{array}$ & $\begin{array}{l}2.34 \pm 0.14 \\
2.96 \pm 0.17\end{array}$ & $\begin{array}{l}2.62 \pm 0.179 \\
2.17 \pm 0.07\end{array}$ & $\begin{array}{l}3.77 \pm 0.378 \\
2.60 \pm 0.08\end{array}$ \\
\hline
\end{tabular}

* Data represent the mean of two to four observations at 5- to 10-min intervals in each subject and are presented as mean \pm SE.

$\ddagger$ Calculated from arterio-hepatic venous differences and estimated hepatic blood flow.

\& Significantly different from the control group, $P<0.001$.

\| Significantly different from the control group, $P<0.05$.

II Significantly different from the control group, $P<0.01$.

Standard statistical calculations have been employed (12), using the paired $t$ test when applicable. Data in the text are given as mean $\pm \mathrm{SE}$.

\section{RESULTS}

Arterial substrate concentrations. Data obtained in the basal state on arterial substrate concentrations in the diabetic and control groups are shown in Tables II and III. The constancy of circulating metabolites in the diabetic group is indicated by the fact that arterial glucose levels were measured on three occasions at 15-min intervals in each subject, and the mean values $( \pm \mathrm{SE})$ were $13.9 \pm 1.3,13.6 \pm 1.4$, and $14.1 \pm 1.3$ mmoles/ liter for the three sampling periods. Similarly, arterial

TABLE III

Arterial Concentration, Arterial-Femoral Venous Differences $(A-F V)$, and Arterial-Hepatic Venous Differences $(A-H V)$ of Plasma Amino Acids in the Basal State in Diabetic and Control Subjects*

\begin{tabular}{|c|c|c|c|c|c|c|c|c|c|}
\hline & \multicolumn{3}{|c|}{ Arterial concentration } & \multicolumn{3}{|c|}{$\mathbf{A}-\mathbf{H V}$} & \multicolumn{3}{|c|}{$A-F V$} \\
\hline & $\begin{array}{c}\text { Diabetics } \\
(n=7)\end{array}$ & $\begin{array}{l}\text { Controls } \\
(n=24)\end{array}$ & $P \ddagger$ & $\begin{array}{c}\text { Diabetics } \\
(\mathrm{n}=7)\end{array}$ & $\begin{array}{l}\text { Controls } \\
(n=17)\end{array}$ & $P \ddagger$ & $\begin{array}{c}\text { Diabetics } \\
(\mathrm{n}=7)\end{array}$ & $\begin{array}{l}\text { Controls } \\
(n=19)\end{array}$ & $P \nsubseteq$ \\
\hline : & \multicolumn{3}{|c|}{ 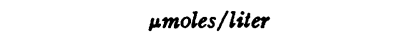 } & \multicolumn{3}{|c|}{ 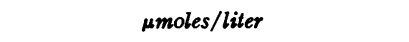 } & \multicolumn{3}{|c|}{ umoles/liter } \\
\hline Taurine & $47.7 \pm 1.5$ & $46.5 \pm 1.2$ & & $2.4 \pm 0.6$ & $2.8 \pm 1.0$ & & $1.9 \pm 1.8$ & $1.2 \pm 1.4$ & \\
\hline Aspartic acid & $7.0 \pm 0.2$ & $10.2 \pm 1.1$ & $<0.01$ & $-0.6 \pm 1.0$ & $-3.1 \pm 0.8$ & $<0.05$ & $1.7 \pm 1.1$ & $-1.2 \pm 1.8$ & \\
\hline Threonine & $93.1 \pm 7.3$ & $110.9 \pm 3.8$ & $<0.05$ & $23.3 \pm 4.5$ & $14.6 \pm 1.3$ & $<0.025$ & $-7.4 \pm 4.3$ & $-11.4 \pm 0.9$ & \\
\hline Serine & $120.9 \pm 4.2$ & $123.5 \pm 4.0$ & & $42.7 \pm 7.4$ & $21.8 \pm 1.8$ & $<0.001$ & $4.1 \pm 5.6$ & $9.9 \pm 4.4$ & \\
\hline Proline & $157.7 \pm 7.1$ & $167.8 \pm 11.1$ & & $22.7 \pm 6.9$ & $4.9 \pm 3.4$ & $<0.002$ & $-7.4 \pm 6.9$ & $-15.9 \pm 4.0$ & \\
\hline Citrulline & $36.9 \pm 2.2$ & $37.7 \pm 1.7$ & & $-8.1 \pm 2.4$ & $-15.7 \pm 2.2$ & $<0.025$ & $5.1 \pm 1.2$ & $4.1 \pm 0.8$ & \\
\hline Glycine & $178.4 \pm 13.3$ & $208.9 \pm 7.2$ & $<0.05$ & $35.1 \pm 9.2$ & $15.6 \pm 3.7$ & $<0.02$ & $-16.9 \pm 8.2$ & $-23.1 \pm 3.5$ & \\
\hline Alanine & $182.7 \pm 5.6$ & $219.8 \pm 7.9$ & $<0.02$ & $119.4 \pm 8.4$ & $90.8 \pm 7.6$ & $<0.02$ & $-64.5 \pm 12.7$ & $-67.9 \pm 6.9$ & \\
\hline$\alpha$-Aminobutyrate & $34.3 \pm 3.4$ & $27.0 \pm 1.9$ & & $1.1 \pm 2.9$ & $-1.3 \pm 2.2$ & & $-1.4 \pm 2.0$ & $1.5 \pm 0.5$ & \\
\hline Valine & $337.4 \pm 11.0$ & $227.9 \pm 5.4$ & $<0.001$ & $3.9 \pm 3.5$ & $-0.5 \pm 2.5$ & & $21.0 \pm 11.6$ & $-7.8 \pm 3.4$ & $<0.001$ \\
\hline Cystine & $104.1 \pm 1.9$ & $98.0 \pm 3.0$ & & $8.9 \pm 3.0$ & $1.3 \pm 3.9$ & & $16.3 \pm 4.0$ & $8.2 \pm 1.8$ & $<0.05$ \\
\hline Methionine & $16.7 \pm 1.2$ & $17.3 \pm 0.4$ & & $7.9 \pm 1.0$ & $4.4 \pm 0.4$ & $<0.001$ & $-1.9 \pm 1.2$ & $-3.3 \pm 0.3$ & \\
\hline Isoleucine & $94.9 \pm 8.9$ & $54.4 \pm 1.5$ & $<0.001$ & $0.6 \pm 2.1$ & $1.4 \pm 1.3$ & & $2.6 \pm 3.5$ & $-2.9 \pm 0.4$ & $<0.02$ \\
\hline Leucine & $196.0 \pm 12.1$ & $121.8 \pm 3.3$ & $<0.001$ & $0.9 \pm 2.2$ & $-2.8 \pm 1.8$ & & $7.1 \pm 7.6$ & $-8.9 \pm 2.2$ & $<0.01$ \\
\hline Tyrosine & $44.4 \pm 1.5$ & $43.3 \pm 1.5$ & & $12.6 \pm 1.3$ & $7.7 \pm 0.6$ & $<0.001$ & $-2.0 \pm 2.2$ & $-3.5 \pm 0.5$ & \\
\hline Phenylalanine & $46.7 \pm 2.2$ & $45.9 \pm 1.2$ & & $7.4 \pm 1.7$ & $3.4 \pm 0.7$ & $<0.02$ & $-3.3 \pm 3.1$ & $-4.7 \pm 0.5$ & \\
\hline
\end{tabular}

* Data are given as mean \pm SE.

$\ddagger$ Probability that the differences between the diabetic and control group are caused by chance alone. 
lactate and pyruvate were determined on two samples drawn at 15-min intervals from each diabetic subject, the mean values $( \pm \mathrm{SE}$ ) for lactate being $0.65 \pm 0.05$ and $0.67 \pm 0.06 \mathrm{mmoles} / \mathrm{liter}$, and for pyruvate, $0.075 \pm 0.004$ and $0.071 \pm 0.004$ mmoles/liter.

As compared to the controls, the arterial level of glucose was 3-3.5 times higher in the patient group. With regard to the various glucose precursors, no significant difference was observed in the arterial concentrations of lactate and pyruvate. However, the concentrations of the key endogenous glycogenic amino acids (7) alanine, glycine, and threonine were significantly reduced in the diabetics. In addition, a decreased level of aspartate was observed in the diabetic group. In contrast the arterial levels of the branched-chain amino acids, valine, leucine, and isoleucine were 50 $90 \%$ higher in the diabetics than in the control group. The arterial blood $\mathrm{pH}$ was $7.38 \pm 0.02$ and $\mathrm{Pco}_{2} 36 \pm 1$ $\mathrm{mm} \mathrm{Hg}$ in the diabetic group, demonstrating a normal acid-base state.

Splanchnic metabolism. The basal rate of splanchnic glucose output, calculated as the product of arterialhepatic venous differences and hepatic blood flow, did not differ significantly between the two groups (Table II). When considered in relation to body weight, glucose output was $3.0 \pm 0.2 \mathrm{mg} / \mathrm{kg}$ per min in the diabetics and $2.4 \pm 0.4 \mathrm{mg} / \mathrm{kg}$ per $\mathrm{min}$ in the controls ( $P$ $>0.1$ ). Marked differences were noted between the diabetic and control groups with respect to splanchnic uptake of precursor substrates. Thus net uptake of lactate and pyruvate was $65-115 \%$ higher in the diabetic group (Table II). Inasmuch as the arterial levels of pyruvate and lactate were not elevated in the diabetics, the increased uptake of these glucose precursors was a result of augmented fractional extraction by the splanchnic vascular bed (Fig. 1).

Of the 16 amino acids studied, consistently positive arterio-hepatic venous differences $(\mathrm{A}-\mathrm{HV})^{1}$ indicating a net uptake were demonstrable in both the diabetic and control subjects for nine amino acids: alanine, serine, glycine, threonine, tyrosine, cystine, methionine, phenylalanine, and taurine (Table III). A significant uptake was also observed for proline in the diabetic group. In accordance with previous findings (13), in both groups, the A-HV for alanine exceeded that of all other amino acids (Table III). Particularly noteworthy is the fact that splanchnic uptake of alanine in the diabetic group exceeded that for the control subjects by $60 \%$ (Fig. 2). Twofold increments in net splanchnic uptake of glycine, serine, threonine, methionine, tyrosine, and phenylalanine were also observed in the diabetics (Fig. 2). Since the arterial concentra-

\footnotetext{
${ }^{1}$ Abbreviation used in this paper: A-HV, arterio-hepatic venous differences.
}

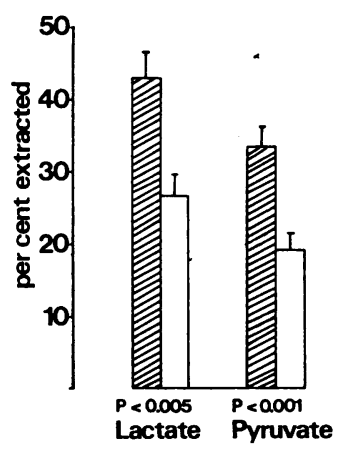

FIGURE 1 Fractional extraction by the splanchnic vascular bed in diabetic subjects (cross-hatched bars) and in controls (open bars) of lactate and pyruvate. Lines at the top of the bars indicate the SE. $P$ values denote the probability that the differences between the groups are a chance occurrence.

tions of alanine, glycine, and threonine were significantly reduced in the diabetics, and were unchanged for the remaining amino acids, the augmented splanchnic amino acid uptake was solely a consequence of increased fractional extraction by the splanchnic bed. As shown in Fig. 3, splanchnic extraction of alanine was $36 \pm 3 \%$ in the control group and $66 \pm 5 \%$ in the diabetics $(P$ $<0.01)$. Two-to threefold increments in fractional extraction were also observed for the remaining glycogenic amino acids (Fig. 3).

Estimated hepatic blood flow was slightly larger in the diabetic group $(1441 \pm 43 \mathrm{ml} / \mathrm{min}, P<0.025)$ than for the control subjects $(1229 \pm 48 \mathrm{ml} / \mathrm{min})$. The arterial-hepatic venous difference for oxygen was also augmented and the calculated splanchnic oxygen uptake

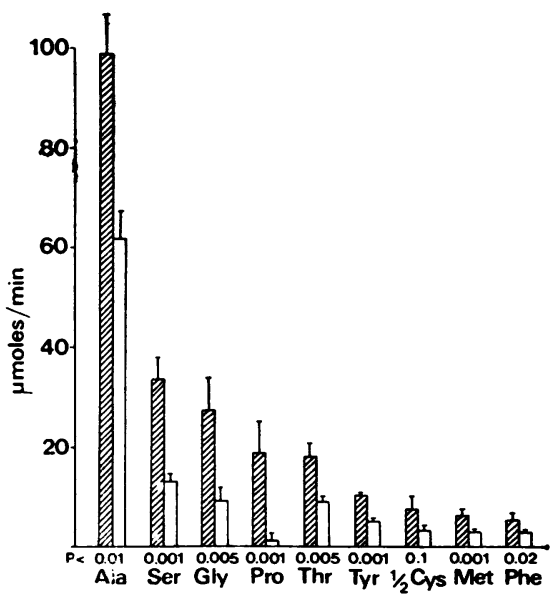

FIGURE 2 Splanchnic uptake of amino acids in the basal state in diabetic subjects (cross-hatched bars) and control subjects (open bars). Lines at the top of the bars indicate the SE. $P$ values denote the probability that the differences between the groups are a chance occurrence. Splanchnic uptakes were calculated from arterio-hepatic venous differences (Table III) and hepatic blood flow. 


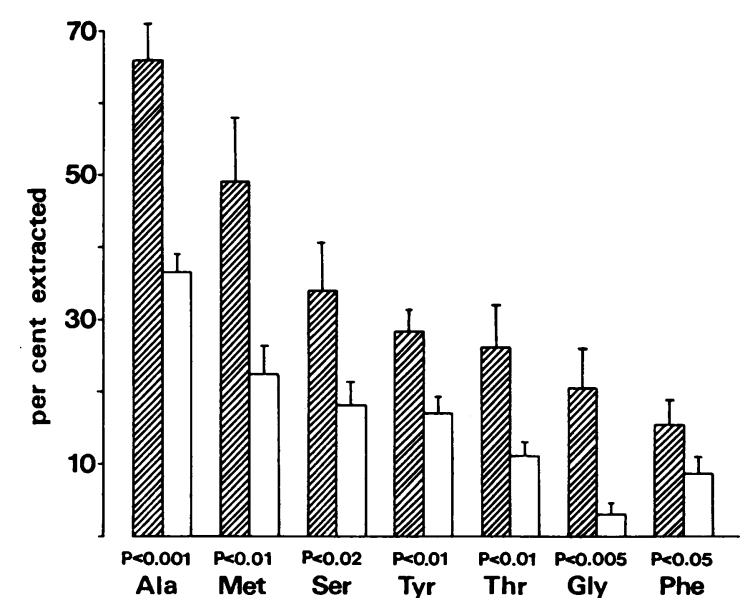

FIgURE 3 Fractional extraction of amino acids by the splanchnic vascular bed in diabetic subjects (cross-hatched bars) and in controls (open bars). Lines at the top of the bars represent the SE. $P$ values represent the probability that the differences between the groups are a chance occurrence.

was approximately $45 \%$ larger in the diabetic group (Table II).

Leg metabolism. There was a consistently positive arterio-femoral venous difference for glucose $(P<$ 0.05) in the diabetic group, which did not differ significantly from that observed in the control group (Table II). The release of lactate and pyruvate from the leg was also similar in the two groups, as was the arterial-venous oxygen difference across the leg (Table II).
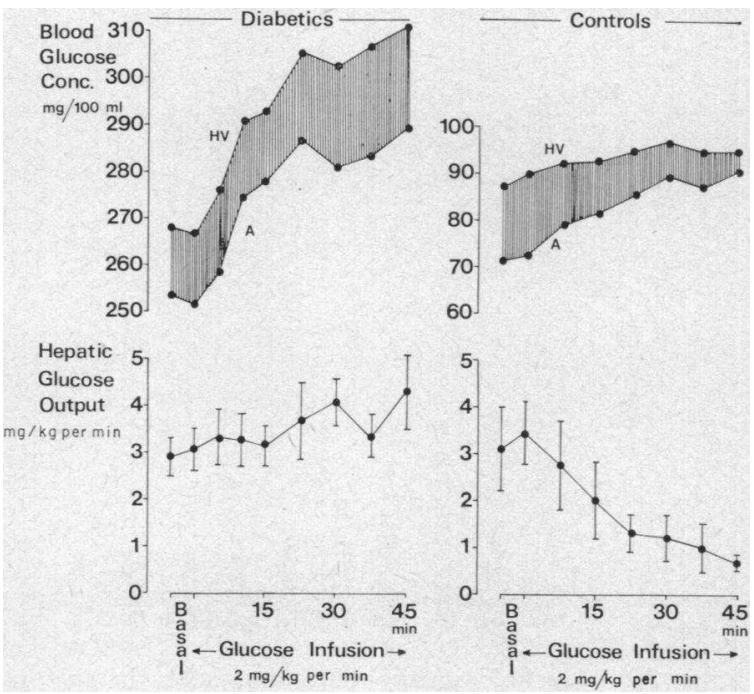

Figure 4 Mean arterial (A) and hepatic venous (HV) glucose concentrations and splanchnic glucose production in the basal state and during infusion of glucose at a rate of $2 \mathrm{mg} / \mathrm{kg}$ per min for $45 \mathrm{~min}$ in six diabetic and seven control subjects. Mean values $\pm \mathrm{SE}$.
The output of most amino acids from the leg tissues, as indicated from the femoral arterial-venous differences, was not significantly different in the two groups (Table III). Discrepancies between the groups were however observed for the branched-chain amino acids, valine $(P<0.001)$, leucine $(P<0.01)$, and isoleucine $(P<0.01)$. Whereas negative arterial-venous differences indicating a net release were observed for the branched-chain amino acids in the control group, in the diabetics the net exchange of these amino acids across the leg was too variable to result in a consistent net output or uptake (Table III).

Response to glucose infusion. The effect of intravenous infusion of glucose at a rate of $2 \mathrm{mg} / \mathrm{kg}$ per min on arterial and hepatic venous glucose concentrations and hepatic glucose production is shown in Fig. 4. In the diabetic group the arterial glucose concentration rose during glucose administration by a mean value of $37 \mathrm{mg} / 100 \mathrm{ml}$ as compared with $18 \mathrm{mg}$ / $100 \mathrm{ml}$ in the control group. Estimated hepatic blood flow did not change in the diabetic group but the arterial-hepatic venous difference for glucose increased slowly during the course of the $45 \mathrm{~min}$ glucose infusion, resulting in a $44 \%$ rise $(P<0.05)$ in net splanchnic glucose output by the end of the infusion period. In the controls, on the other hand, the arterialhepatic venous glucose difference was markedly reduced, resulting in an $80 \%$ inhibition of net hepatic glucose production. As reported previously (7), in association with the infusion of glucose in the control group the mean arterial insulin level rose from $9.0 \pm 1.1$ $\mu \mathrm{U} / \mathrm{ml}$ in the basal state to $15.0 \pm 2.7 \mu \mathrm{U}$ at the end of the infusion. The radioimmunoassay used for the determination of insulin could not be applied in the diabetic subjects, all of whom had been on insulin treatment for more than a year. The arterial glucagon concentration was measured in the basal state and during the administration of glucose in four diabetic patients and in two healthy controls (Fig. 5). The basal values closely agree with previous findings in normal and diabetic patients using the same immunoassay (14). The arterial glucagon concentration showed no consistent change during the glucose infusion (Fig. 5).

There was no significant change in the splanchnic uptake of lactate and pyruvate during glucose infusion in either group. In a like manner splanchnic amino acid uptake remained constant in the diabetic group (Table IV) and in the controls (7) in association with the $2 \mathrm{mg} / \mathrm{kg}$ per min glucose infusion.

\section{DISCUSSION}

In the present study the rate of splanchnic glucose production did not differ significantly between the diabetic patients and the controls in spite of markedly elevated 
blood glucose levels in the diabetic group. This finding is in agreement with previous observations in nonketotic hyperglycemic patients with diabetes studied by means of the hepatic venous catheter technique $(2,3)$ or by isotopic methods for the estimation of blood glucose replacement rate (4-6). In contrast to these findings, patients in a more severe diabetic state as indicated by ketoacidosis (15) or hyperglycemia exceeding $400 \mathrm{mg} / 100$ $\mathrm{ml}$ (16) have an accelerated rate of splanchnic glucose production. The failure to observe an elevation in hepatic glucose output in the curernt study thus may be due to a residual effect of the last dose of insulin which served to prevent ketosis as well as an increase in glucose release at the time of study.

Of particular interest is the fact that the current investigation provides evidence of altered gluconeogenesis in diabetes even when total hepatic glucose production is within the range observed in control subjects. Firstly, significantly greater net splanchnic uptakes of lactate and pyruvate were observed in the diabetic group suggesting an increase in Cori cycle activity. This observation agrees well with the findings of increased conversion of lactate $-{ }^{14} \mathrm{C}$ and pyruvate $-{ }^{14} \mathrm{C}$ into blood glucose in diabetic patients $(17,18)$, whereas lactate conversion to $\mathrm{CO}_{2}$ is reduced (19). The source of the extra lactate and pyruvate generated for heightened Cori cycle activtiy in the diabetics is not, however, readily apparent,

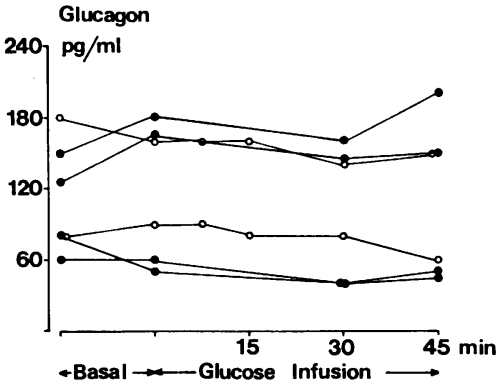

Figure 5 Arterial glucagon concentration in diabetic subjects (filled circles) and healthy subjects (open circles) in the basal state and during administration of glucose at a rate of $2 \mathrm{mg} / \mathrm{kg}$ per $\mathrm{min}$.

inasmuch as peripheral output of these metabolites was not increased nor were arterial levels reduced. Secondly, the enhanced splanchnic uptake of alanine and other glucogenic amino acids in diabetes is further evidence of an accelerated rate of hepatic gluconeogenesis in this condition. The occurrence of a negative arterial-portal venous difference has previously been demonstrated for alanine in man (9), indicating a release of alanine from the gut, so that the present measurements of splanchnic amino acid uptake probably underestimate rather than exaggerate the true hepatic uptake. Thus with respect to each of the glucose precursors measured, significant

TABLE IV

Arterial Concentration, Arterial-Femoral Venous $(A-F V)$ Concentration Difference, and Splanchnic Exchange of Plasma Amino Acids in the Basal State and after Glucose Infusion in Diabetic Subjects

\begin{tabular}{|c|c|c|c|c|c|c|}
\hline & \multicolumn{2}{|c|}{ Arterial concentration } & \multicolumn{2}{|c|}{$A-F V$} & \multicolumn{2}{|c|}{ Splanchnic exchange } \\
\hline & Basal & Postglucose* & Basal & Postglucose* & Basal & Postglucose* \\
\hline & \multicolumn{2}{|c|}{ 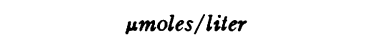 } & \multicolumn{2}{|c|}{$\mu m \rho l e s /$ liter } & \multicolumn{2}{|c|}{ Mmoles/min } \\
\hline Taurine & $48.2 \pm 1.6 \ddagger$ & $44.3 \pm 2.1$ & $2.5 \pm 2.1$ & $-2.8 \pm 1.9$ & $1.8 \pm 0.4$ & $-0.3 \pm 1.9$ \\
\hline Aspartic acid & $7.0 \pm 0.3$ & $6.0 \pm 0.51$ & $2.0 \pm 1.2$ & $0.2 \pm 1.9$ & $-0.1 \pm 0.9$ & $-0.4 \pm 0.4$ \\
\hline Threonine & $93.7 \pm 8.6$ & $85.7 \pm 8.0$ & $-7.7 \pm 5.1$ & $-15.2 \pm 5.8$ & $19.6 \pm 2.4$ & $21.6 \pm 3.9$ \\
\hline Serine & $121.3 \pm 5.0$ & $112.8 \pm 4.58$ & $3.5 \pm 6.7$ & $-8.2 \pm 7.3$ & $35.5 \pm 4.9$ & $32.7 \pm 3.1$ \\
\hline Proline & $161.8 \pm 6.9$ & $152.2 \pm 6.0$ & $-7.2 \pm 8.1$ & $-20.0 \pm 8.8$ & $21.7 \pm 6.7$ & $24.4 \pm 6.2$ \\
\hline Citrulline & $36.5 \pm 2.6$ & $34.5 \pm 1.8$ & $5.0 \pm 1.4$ & $4.3 \pm 3.0$ & $-5.8 \pm 2.1$ & $-5.4 \pm 1.6$ \\
\hline Glycine & $179.3 \pm 15.7$ & $170.5 \pm 14.5$ & $-15.8 \pm 9.6$ & $-23.2 \pm 9.8$ & $23.4 \pm 6.0$ & $26.0 \pm 6.6$ \\
\hline Alanine & $180.5 \pm 6.1$ & $180.0 \pm 10.6$ & $-64.7 \pm 15.0$ & $-64.3 \pm 19.4$ & $99.0 \pm 9.4$ & $104.0 \pm 15.3$ \\
\hline$\alpha$-Aminobutyrate & $35.0 \pm 3.9$ & $37.3 \pm 3.7$ & $-1.3 \pm 2.4$ & $-1.2 \pm 4.0$ & $0.1 \pm 2.7$ & $6.3 \pm 2.6$ \\
\hline Valine & $340.6 \pm 15.2$ & $338.0 \pm 14.7$ & $24.8 \pm 13.0$ & $8.2 \pm 19.1$ & $1.7 \pm 2.9$ & $1.0 \pm 6.2$ \\
\hline$\frac{1}{2}$ Cystine & $103.7 \pm 2.2$ & $99.0 \pm 2.9$ & $18.5 \pm 3.9$ & $10.5 \pm 4.4$ & $8.9 \pm 2.6$ & $7.2 \pm 2.9$ \\
\hline Methionine & $16.7 \pm 1.4$ & $14.5 \pm 1.31$ & $-2.2 \pm 1.4$ & $-4.0 \pm 1.2$ & $6.6 \pm 1.4$ & $5.2 \pm 1.1$ \\
\hline Isoleucine & $98.8 \pm 9.4$ & $100.2 \pm 9.4$ & $2.2 \pm 4.1$ & $-0.3 \pm 5.4$ & $-1.3 \pm 1.7$ & $0.2 \pm 2.2$ \\
\hline Leucine & $203.8 \pm 10.9$ & $207.0 \pm 12.6$ & $8.7 \pm 8.8$ & $0.7 \pm 11.1$ & $-0.5 \pm 1.7$ & $0.2 \pm 4.1$ \\
\hline Tyrosine & $45.7 \pm 1.0$ & $42.3 \pm 1.40 \S$ & $-2.2 \pm 2.6$ & $-5.3 \pm 2.9$ & $10.0 \pm 1.1$ & $10.3 \pm 1.9$ \\
\hline Phenylalanine & $48.0 \pm 2.1$ & $49.2 \pm 1.5$ & $-3.3 \pm 3.7$ & $-6.3 \pm 3.1$ & $5.8 \pm 1.5$ & $5.8 \pm 0.8$ \\
\hline
\end{tabular}

* Postglucose samples were obtained after $45 \mathrm{~min}$ infusion of glucose at a rate of $2 \mathrm{mg} / \mathrm{kg}$ per min.

$\ddagger$ Data are given as mean $\pm \mathrm{SE}, \mathrm{n}=6$.

\& Significantly different from basal value, $P<0.05$ (paired $t$ test). 
TABLE $\mathrm{V}$

Balance of Glucose and Glucogenic Substrates across the Splanchnic Vascular Bed in the Basal State in Diabetic and Control Subjects

\begin{tabular}{lcc}
\hline & Diabetics & Controls \\
\hline Glucose production* & 1.07 & 0.95 \\
Uptake of & & \\
(1) Lactate $\ddagger$ & 0.205 & 0.125 \\
(2) Pyruvate & 0.019 & 0.008 \\
(3) Amino acids $¥ \S$ & 0.114 & 0.053 \\
(4) Glycerol $¥ \|$ & - & 0.016 \\
Sum of (1)-(4) & 0.338 & 0.202 \\
Per cent of glucose production & 32 & 21 \\
\hline
\end{tabular}

* Data are presented as millimoles per minute.

$\ddagger$ Expressed as glucose equivalents in millimoles per minute. $\S$ Sum of splanchnic uptake of amino acids for which a statistically significant uptake was found (Table III).

\| Glycerol uptake was not measured in the diabetic group but has been previously reported for the control group (9).

increments in splanchnic extraction were observed in the diabetics.

In Table $\mathrm{V}$ the balance data for glucose and glucose precursors across the splanchnic bed are presented. Although glutamine is normally extracted by the splanchnic bed (20), it is not included in the calculation because the column chromatographic technique employed in the present study precluded accurate determination of this amino acid. As shown, total precursor uptake is significantly higher in the diabetic group as compared to the controls, while net glucose production is equivalent in the two groups. From the quantitative data in Table V it can be seen that approximately $20 \%$ of hepatic glucose output could be accounted for by gluconeogenesis in the controls, whereas over $30 \%$ was derivable from precursor substrates in the diabetics. It should be noted that the balance data in the diabetic group (Table V) does not include observations on the splanchnic uptake of glycerol which was not measured in the present study. The discrepancy between the controls and diabetics with respect to the proportion of glucose derivable from gluconeogenesis is thus likely to be further accentuated were data available on glycerol uptake in the diabetics. Supporting the conclusion of increased gluconeogenesis in the diabetics is the greater rate of oxygen uptake in this group (Table II). Accelerated oxidation of fatty acids which generally accompanies augmented glucose synthesis (21) may have contributed to the greater splanchnic oxygen consumption observed in the patient group. Finally, the balance data indicate that the portion of the hepatic glucose production not accounted for by gluconeogenesis and presumably covered by glycogenolysis, is smaller in the diabetic group than in the controls.
The increased hepatic utilization of glucose precursors in diabetes could be a consequence of either greater substrate availability or augmented hepatic extraction of circulating substrates. Inasmuch as the diabetic group displayed significant reductions of plasma alanine, glycine, and threonine, while the levels of the remaining glycogenic amino acids and lactate and pyruvate were unchanged, there is no evidence of increased substrate availability in these patients. As shown in Figs. 1 and 3, augmented hepatic extraction was in fact responsible for the increased uptake of all the glucose precursors studied. Whereas $36 \%$ of the alanine presented to the liver was extracted in the control group; $66 \%$ was taken up in the diabetic group. Two- to threefold increments in fractional extraction were also noted for the remaining amino acids and a $60-75 \%$ increase in the splanchnic extraction of lactate and pyruvate was seen. Thus it can be concluded that the diabetic state with lack of adequate insulin is characterized by an augmented hepatic uptake of glucogenic precursors as a consequence of altered intrahepatic metabolic events as opposed to an increased availability of precursor substrates. Supporting this conclusion is the demonstration that insulin-induced inhibition of gluconeogenesis is primarily a result of an hepatic effect on precursor uptake rather than a consequence of a peripheral action on substrate supply (7).

The current observations of a decrease in the arterial concentration of alanine, glycine, and threonine and an increase in the levels of the branched-chain amino acids are consistent with previous findings in ketotic (22) and nonketotic diabetics (23). Augmented hepatic utilization of key glucogenic amino acids probably serves to explain the lowered arterial concentrations of these amino acids, inasmuch as the arterial-femoral venous differences were similar in the diabetic and control groups. Thus an increase in hepatic demand for alanine and other glycogenic amino acids exceeds the supply from muscle tissue $(24,25)$ and as a consequence the arterial level falls. A similar sequence has been postulated to account for the development of hypoalaninemia in starvation (26). The background to the rise in the concentrations of the branched-chain amino acids in diabetes is less clear. It has been suggested that these amino acids may be released from the liver in diabetes $(27,28)$, but this can hardly be the case since no significant splanchnic output was found in the present study for either valine, leucine, or isoleucine. As shown in Table I, none of the diabetic patients was significantly overweight, so that obesity, which of itself causes an elevation of the branched-chain amino acids (29), can be ruled out as a causal factor in the present study. Increased mobilization of branched-chain amino acids from peripheral protein stores has also been postulated, particularly in diabetic ketoacidosis (22). However, the mean arterial-femoral 
venous difference for all three of these amino acids was positive in the patient group and differed significantly from the negative findings in the controls. There is thus no evidence of a consistent release of the branched-chain amino acids by leg tissue in the diabetics. The augmented arterial concentration of these amino acids thus remains to be explained.

The effects of glucose infusion on splanchnic glucose balance in the diabetics (Fig. 4) are of interest inasmuch as the liver in normal man has been shown to be highly sensitive to small increments in the arterial glucose concentration and it has been suggested that this is due to glucose-induced changes in endogenous insulin secretion (7). Thus, intravenous infusion of glucose in normal subjects at a rate of $2 \mathrm{mg} / \mathrm{kg}$ per min causes no more than a twofold increase in arterial insulin levels, yet hepatic glucose output is reduced by approximately $80 \%$. In contrast, infusion of glucose at the same rate in diabetic subjects in the present study did not yield a reduction of hepatic glucose output in spite of the fact that the arterial glucose concentration rose twice as much as in the controls (Fig. 4). These data thus support the conclusion that the exquisite sensitivity of the liver to infusion of glucose in normal man (7), is a result of glucose-induced secretion of insulin, rather than a consequence of hyperglycemia per se. In this respect the current findings are in agreement with earlier work by Madison, et al. in dogs with portacaval shunts (8).

The basal glucagon levels measured in the present study are in good agreement with previous findings in diabetic and healthy subjects $(11,14)$. The possibility has been considered that factors other than insulin, such as inhibition of glucagon secretion, may contribute to the effects of glucose infusion on hepatic glucose output in normal man (7). As far as can be ascertained from measurements of arterial concentrations, there is no indication from the present results that changes in glucagon secretion are responsible for the splanchnic response to glucose infusion in diabetic patients or healthy controls. However, the possibility that infusion of glucose at $2 \mathrm{mg} / \mathrm{kg}$ per min alters portal vein glucagon levels cannot be excluded at the present time.

\section{ACKNOWLEDGMENTS}

This work was supported by grants from the Tore Nilson Foundation for Medical Research, the Swedish Medical Research Council (B71-19X-3108), and the U. S. Public Health Service (AM-13526).

\section{REFERENCES}

1. Wahren, J., P. Felig, E. Cerasi, and R. Luft. 1972. Hepatic glucose and amino acid metabolism in diabetes. Isr. J. Med. Sci. In press. (Abstr.)
2. Myers, J. D. 1950. Net splanchnic glucose production in normal man and in various disease states. J. Clin. Invest. 29: 1421.

3. Bearn, A. G., B. H. Billing, and S. Sherlock. 1951. Hepatic glucose output and hepatic insulin sensitivity in diabetes mellitus. Lancet. 2: 698.

4. Shreeve, W. W., N. Baker, M. Miller, R. A. Shipley, G. E. Incefy, and J. W. Craig. 1956. $C^{14}$ studies in carbohydrate metabolism. II. The oxidation of glucose in diabetic human subjects. Metab. (Clin. Exp.). 5: 22.

5. Reichard, G. A., Jr., N. F. Moury, N. J. Hochella, A. L. Patterson, and S. Weinhouse. 1963. Quantitative estimation of the Cori cycle in the human. J. Biol. Chem. 238: 495.

6. Manougian, E., M. Pollycove, J. A. Linfoot, and J. H. Lawrence. 1964. $C^{14}$ glucose kinetic studies in normal, diabetic and acromegalic subjects. J. Nucl. Med. 5: 763.

7. Felig, P., and J. Wahren. 1971. Influence of endogenous insulin secretion on splanchnic glucose and amino acid metabolism in man. J. Clin. Invest. 50: 1702.

8. Madison, L. L., B. Combes, R. Adams, and W. Strickland. 1960. Physiological significance of the secretion of endogenous insulin into the portal circulation. III. Evidence for a direct immediate effect of insulin on the balance of glucose across the liver. J. Clin. Invest. $39: 507$.

9. Felig, P., and J. Wahren. 1971. Amino acid metabolism in exercising man. J. Clin. Invest. 50: 2703.

10. Wahren, J., P. Felig, G. Ahlborg, and L. Jorfeldt. 1971. Glucose metabolism during leg exercise in man. J. Clin. Invest. 50: 2715.

11. Aguilar-Parada, E., A. M. Eisentraut, and R. H. Unger. 1969. Pancreatic glucagon secretion in normal and diabetic subjects. Amer. J. Med. Sci. 257: 415.

12. Snedecor, G. W. 1956. Statistical Methods. Iowa State University Press, Ames. 5th edition. 35.

13. Carlsten, A., B. Hallgren, R. Jagenburg, A. Svanborg, and L. Werkö. 1967. Arterio-hepatic venous difference of free fatty acids and amino acids. Acta Med. Scand. $181: 199$.

14. Müller, W. A., G. R. Faloona, E. Aguilar-Parada, and R. H. Unger. 1970. Abnormal alpha-cell function in diabetes. Response to carbohydrate and protein ingestion. N. Engl. J. Med. 283: 109.

15. Bondy, P. K., W. L. Bloom, V. S. Whitner, and B. W. Farrar. 1949. Studies of the role of the liver in human carbohydrate metabolism by the venous catheter technic. II. Patients with diabetic ketosis, before and after the administration of insulin. J. Clin. Invest. 28: 1126 .

16. Forbath, N., and G. Hetenyi, Jr. 1966. Glucose dynamics in normal subjects and diabetic patients before and after a glucose load. Diabetes. 15: 778 .

17. McManus, J. R., P. Sweeney, and R. E. Olson. 1961. Metabolism of pyruvate-2-C $\mathrm{C}^{14}$ in normal and diabetic humans. Fed. Proc. 20: 191.

18. De Meutter, R. C., and W. W. Shreeve. 1963. Conversion of DL-lactate-2-C $C^{14}$ or $-3-C^{14}$ or pyruvate-2-C ${ }^{14}$ to blood glucose in humans: effects of diabetes, insulin, tolbutamide, and glucose load. J. Clin. Invest. 42: 525.

19. Shreeve, W. W., R. C. DeMeutter, and Y. Shigeta. 1964. Diabetes, insulin, tolbutamide and glucose load in the degradation of $\mathrm{C}^{14}$ labeled lactate and pyruvate. Diabetes. $13: 615$

20. Marliss, E. B., T. T. Aoki, T. Pozefsky, A. S. Most, and G. F. Cahill, Jr. 1971. Muscle and splanchnic gluta- 
mine and glutamate metabolism in postabsorptive and starved man. J. Clin. Invest. 50: 814.

21. Ruderman, N. B., C. J. Toews, and E. Shafrir. 1969. Role of free fatty acids in glucose homeostasis. Arch. Intern. Med. 123: 299.

22. Felig, P., E. Marliss, J. L. Ohman, and G. F. Cahill, Jr. 1970. Plasma amino acid levels in diabetic ketoacidosis. Diabetes. 19 : 727.

23. Carlsten, A., B. Hallgren, R. Jagenburg, A. Svanborg, and L. Werkö. 1966. Amino acids and free fatty acids in plasma in diabetes. I. The effect of insulin on the arterial levels. Acta Med. Scand. 179: 361.

24. London, D. R., T. H. Foley, and C. G. Webb. 1965. Evidence for the release of individual amino acids from resting human forearm. Nature (London). 208: 588.
25. Pozefsky, T., P. Felig, J. D. Tobin, J. S. Soeldner, and G. F. Cahill, Jr. 1969. Amino acid balance across tissues of the forearm in postabsorptive man. Effects of insulin at two dose levels. J. Clin. Invest. $48: 2273$.

26. Felig, P., O. E. Owen, J. Wahren, and G. F. Cahill, Jr. 1969. Amino acid metabolism during prolonged starvation. J. Clin. Invest. 48: 584.

27. Schimassek, H., and W. Gerok. 1965. Control of the levels of free amino acids in plasma by the liver. Biochem. Z. 343 : 407.

28. Mallette, L. E., J. H. Exton, and C. R. Park. 1969. Control of gluconeogenesis from amino acids in the perfused rat liver. J. Biol. Chem. 244: 5713.

29. Felig, P., E. Marliss, and G. F. Cahill, Jr. 1969. Plasma amino acid levels and insulin secretion in obesity. $N$. Engl. J. Med. 281 : 811. 